\title{
USAGE OF STARCH IN LEATHER MAKING
}

\author{
CIGDEM KILICARISLAN OZKAN, HASAN OZGUNAY \\ Faculty of Engineering, Department of Leather Engineering, Ege University, Bornova 35100, \\ Turkey,cigdem.kilicarislan@ege.edu.tr,hasan.ozgunay@ege.edu.tr
}

\begin{abstract}
In recent years, various industries begin to head towards cleaner production due to increasingly restrictive regulations. Therefore, production from natural and renewable sources has become more important. Starch is a remarkable raw material because it is abundant, inexpensive and biodegradable natural polymer. The use of natural starch has remained limited, to be usually for food purposes, until recent decades. However, the usage of starch has increased significantly over the last few decades; via modification some of the properties of the starch and it has found wide range of applications in many industries such as plastics, agriculture, pharmaceutics, adhesive, textile, paper and food. In recent years, several studies have taken part in literature on possible use of modified starches also in leather industry - especially in tanning and retanning processes to ensure cleaner production. And it seems that starch products that modified with various methods in accordance their field of use will find more interest and use in leather making. For this reason in the present paper it is aimed to make an overview on the structure of starch as a renewable and natural resource and its potential applications in leather making.
\end{abstract}

Keywords: starch, structure, leather making

\section{INTRODUCTION}

In leather processing, raw skin/hide are transformed into leather by means of a series of chemical and mechanical operations. Tanning is the main process that converts the skin into leather material (Beena et al., 2011). Basic chromium sulphate salts are the most commonly used tanning agents in leather industry for many years. However, since chromium is a heavy metal and correspondingly its potentially harmful effects on soil, water and organisms, recent trends in leather tanning aimed towards avoiding chrome tannage due to environmental legislation and existing quantities of high grade chrome ore reserves. So, synthesizing green leather tannage has been paid more attention than ever (Lv et al., 2012). The usage of natural, biodegradable and environmental friendly products in retanning and finishing processes also will contribute to reduction of waste generated by leather industry. Therefore, the production of chemicals that will be used in leather making from natural and renewable sources is being paid importance.

Starch is a kind of rich, biodegradable, environmentally friendly and renewable resource, and is an important raw material made for green chemicals. It's one of the main research directions that modified starch is used as green chemical material now and in the future (Liu et al., 2009).

In this paper, it is aimed to make an overview on structure of starch as a renewable and natural resource and its promising applications in leather making.

\section{THE STRUCTURE OF STARCH}

In plants, glucose is first produced via photosynthesis, and then stored in the form of starch granules (Song, 2011). It is widely distributed in the form of tiny granules as the major reserve carbohydrate in stems, roots, grains and fruits of all forms of green leafed plants (Neelam et al., 2012). The size and shape of starch granules vary for different biological sources (Song, 2011). Starch is made up of two fractions: amylose which is made up of essentially $\alpha$ - $(1 \rightarrow 4)$ D-glucopyranosyl units and amylopectin which is made 
up of a large number of short chains linked together at their reducing end side by a $\alpha$ $(1 \rightarrow 6)$ linkage (Kaur et al., 2012). The structure of a starch macromolecule in most crops is a mixture of $20-30 \%$ amylose and $70-80 \%$ amylopectin. The degree of polymerization of starch is about 160 to 6000 , and its relative molecular weight is about 25000 to 1000000 (Lu et al., 2005). It should be noted that the molecular structure (linear or branched) and molecular weight of starch molecules in a crop have a significant influence on its processability for various applications (Biresaw and Shogren, 2008).

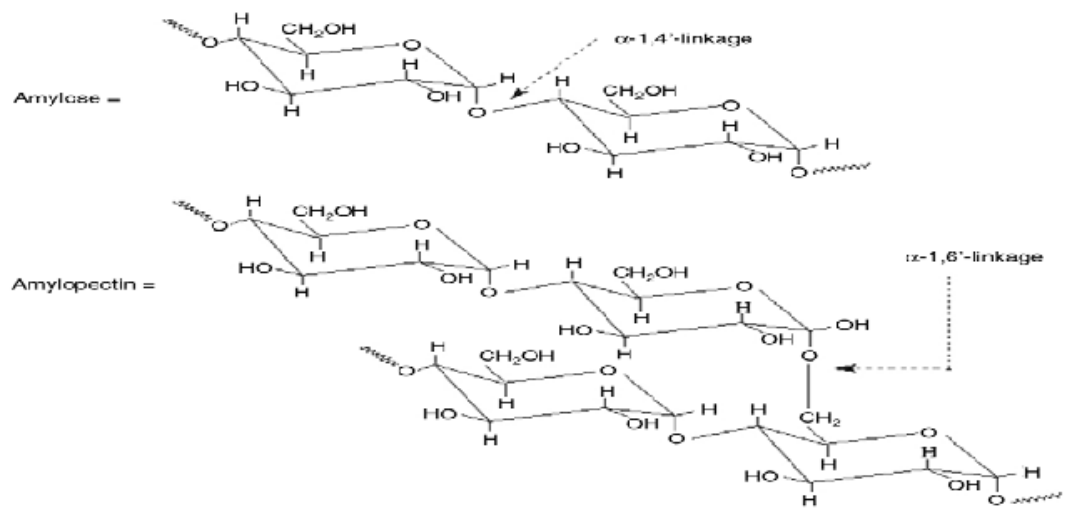

Figure 1. The structure of amylose and amylopectin

Starch itself is poor in processability, also poor in the dimensional stability and mechanical properties for its end products. Therefore, native starch is not used directly (Lu et al., 2009). Although some unsuitable characteristics of native starches limit their use in most applications, starch modifications can eliminate or reduce these undesirable traits (Chan et al., 2011). The available hydroxyl groups on the starch chains potentially exhibit reactivity specific for alcohols. In other words, they can be oxidized and reduced, and may participate in the formation of hydrogen bonds, ethers and esters ( $\mathrm{Lu}$ et al., 2009).

There are three hydroxyls in 2, 3, 6 placement in each dehydrated glucose unit. Among these, the primary-hydroxyl in $\mathrm{C} 6$ has the strongest reactivity and then there are the secondary hydroxyls in C2 and C3 (Zhen and Ma, 2000). Hydroxyl groups have a particular affinity for other hydroxyl groups and can serve as a driving force in bringing starch chains together in an ordered manner through hydrogen bonding. Where such ordering occurs, crystalline regions are deposited in the granule. The remaining regions of unordered starch are referred to as amorphous. It is the crystalline regions that give a granule its structure and facilitate identification of raw starch (Murphy, 2000). The processing of native starch is often followed by disrupting its granular structure. When heated in the presence of water the starch granules swell, lose crystallinity and amorphous interior of granule diffuses into solution (Wilpiszewska and Spychaj, 2007). Therefore, the hydroxyl groups in starch structure can react with the different modifier reagents to enhance their processability for using different industrial areas. 
ICAMS $2016-6^{\text {th }}$ International Conference on Advanced Materials and Systems

\section{USAGE OF STARCH IN LEATHER MAKING}

Although the studies on possible use of starch in tanning process are rare, most of them is related to tanning of pelts with dialdehyde starch which can be produced by periodate oxidation of native starch. From the literature search, it was also noticed that the studies on possible use of starch as retanning and finishing agents have been increased.

Some of the studies in these fields are summarized below:

Celades et al. (1990) introduced a new method for a chrome-free tanning process. The authors gave the tanning steps as pre-tanning with oxidized starch, tanning with titanium salt, neutralization, retanning, dyeing and finishing. The authors thought that pre-tanning with selectively oxidized starch enhanced the interaction of titanium with collagen and the leather had excellent texture and handle.

Lv et al. (2012) studied on modifying of corn starch by glutaraldehyde and used it in tanning process. From the results they concluded that the modification of starch by glutaraldehyde was an efficient method to significantly improve its tanning property and the shrinkage temperature of the tanned leather was $85.2^{\circ} \mathrm{C}$. Accordingly, the authors thought that the modified starch could be used as a tanning agent and the pollution produced by chrome tanning could be significantly decreased.

Kanth et al. (2006) studied on stabilization of collagen by dialdehyde starch (DAS). DAS samples were autoclaved before the tanning experiments. The authors specified that autoclaving of DAS was resulting hydrolysis to lower molecular weight oligomeric species. These lower molecular weight species showed better tanning properties compared to un-autoclaved DAS and similar effect was also observed on use of DAS in alkaline conditions. It was stated that the leather samples tanned with autoclaved dialdehyde starch at high $\mathrm{pH}$ values had shrinkage temperatures higher than $84{ }^{\circ} \mathrm{C}$ and the leathers exhibited high stability against collagenase.

Tanning ability of graft copolymer of phenols and starch with horseradish peroxidase (HRP) catalysis was investigated by Lv et al. (2011). From the application results, the authors concluded that the phenols and starch graft copolymer had a good selective filling property and the retanned leather had an excellent thickening rate with higher shrinkage temperature.

Liu et al. (2009) synthesized a starch-polyacrylamide graft copolymer by means of HRP and graft copolymer was used in retanning process. From the evaluation of the results they have concluded that the increase of shrinkage temperature of the retanned leather proved that the graft copolymer played a certain role for wet blue, the thickness of retanned leather increased; also graft copolymer had a good selective filling property. It was also pointed out that the retanned leather had many advantages, including an excellent increased rate of thickness, good dyeing effect and eligible mechanical properties.

Lu et al. (2005) studied on graft copolymerization of oxidizing degradation of starch with acrylic acid, acrylonitrile and acrylamide as a leather retanning agent. They emphasized that the graft copolymer retanning had exceptional selective filling characteristics and could improve the uniformity of retanned leathers. It was also denoted that retanned leather had excellent softness, tightness and fullness, and its mechanical properties such as tensile, tear strength and elongation at break were improved. The authors also specified that the graft copolymer retanning will also be, biodegradable to some extent, and may reduce the environmental pollution caused by acrylic retans. 
In another research, Xiaosheng et al. (2012) obtained two kinds of oligosaccharides by single (hypochloric acid) and double (hypochloric acid and hydrogen peroxide) oxidation. They used these products to fill wet-blue leather and determined their filling properties. As conclusion of their research the authors have remarked that the wet-blue leather samples filled with both oxidized starches had low moisture contents, good vapor permeability, and good separation characteristics of fibre bundles. Additionally it was stated that the application of double oxidized starch filling had favorable prospects for improving the sensorial characteristics of chromium tanned leather.

Beena et al. (2011) studied on possible use of graft starch in finishing and graftstarch products were used in finishing of leather as alternate for other leather finishing binders and it was reported that these products will be useful to minimize the pollution by other acrylic binders, etc. Regarding possible use of modified starch in finishing in A German patent (DE2, 756, 488) it was also reported that sodium carboxy methyl starch could improve the air-permeability of leather when it was used in finishing processes (Zhen and Ma, 2000).

\section{CONCLUSION}

In spite of taking many precautions and making attempts to develop more ecological way of production leather industry is one of the industries being debated widely due to its effluents and wastes having potential threats environmentally and day after day many stringent stipulations are being put into effect regarding this issue. In order to accord with these increasing restrictive regulations and improve environmental friendly products by more ecological ways of production, many researches are being started and conducted endlessly. In this point of view; to us, considering the unique properties of starch i.e. being abundant, inexpensive and biodegradable, it seems that it has a huge potential to be utilized in leather processing for many purposes. Despite native starch itself is poor in processability and it is not convenient to be used directly in leather processing, from the literature survey it is known that some unsuitable characteristics of native starches can be eliminated and can be modified in accordance with proposed field of use and many of the issues being debated can be overcome by including it in to leather processing.

\section{REFERENCES}

Beena, Z., Uzma, N. and Barkat, A.S. (2011), "Utilization of Starch in Leather Processing: An EnvironmentFriendly Polymer", Science, Technology \& Development, 30/2, 12-14.

Biresaw, G. and Shogren, R. (2008), "Friction Properties of Chemically Modified Starch", Journal of Synthetic Lubrication, 25, 17-30.

Celades et al. (1990), AQEIC Bol. Tech., 41(4), 190.

Chan, H.T., Leh, C.P., Bhat, R., Senan, C., Williams, P.A. and Karim, A.A. (2011), "Molecular structure, rheological and thermal characteristics of ozono-oxidized starch". Food Chemistry, 126, 1019-1024.

German patent, DE2, 756, 488.

Kanth, S.V., Madhan, B., Rao, J.R., Nair, B.U., Sadulla, S. and Ramasami, T. (2006), "Studies on the Stabilization of Collagen Using Dialdehyde Starch: Part I: Effect of Autoclaving on Dialdehyde Starch", Journal of the American Leather Chemists Association, 101/12, 444-453.

Kaur, B., Ariffin, F., Bhat, R. and Karim, A.A. (2012), "Progress in starch modification in the last decade", Food Hydrocolloids, 26, 398-404.

Liu, G, Lv, S. and Ma, Y. (2009), "Synthesis and Leather-tanning Properties of a Starch-polyacrylamide Graft Copolymer by Means of HRP”, http://www.aaqtic.org.ar/congresos/china2009/download/2-4/2-122.pdf 
ICAMS $2016-6^{\text {th }}$ International Conference on Advanced Materials and Systems

Lu, S., Liang, G., Ren, H., Wang, J. and Yang, Q. (2005), "Synthesis and application of graft copolymer retannage of degraded starch and vinyl monomers", Journal of the Society of Leather Technologies and Chemists, 89/2, 63-66.

Lu, D.R., Xiao, C.M. and Xu, S.J. (2009), "Starch-based completely biodegradable polymer materials", Express Polymer Letters, 3/6, 366-375.

Lv, S., Gong, R., Duan, J., Ma, Y. and Gao, R. (2011), "Preparation and Properties of Graft Copolymer of Phenols and Starch with HRP Catalysis", Advanced Materials Research, 201/203, 2825-2828.

Lv, S., Gong, R. and Hu, J. (2012), "Study on Modified Starch by Glutaraldehyde and Its Properties and Application", Advanced Materials Research, 455/456, 575-581.

Murphy, P. (2000), "Starch", in Handbook of Hydrocolloids, CRC Press.

Neelam, K., Vigay, S. and Lalit, S. (2012), "Various techniques for the modification of starch and the applications of its derivatives", International Research Journal of Pharmacy, 3/5, 25-31.

Song, D. (2011), Starch Crosslinking for Cellulose Fiber Modification and Starch Nanoparticle Formation, In Partial Fulfillment of the Requirements for the Degree Doctor of Philosophy in the School of Chemical and Biomolecular Engineering, Georgia Institute of Technology.

Wilpiszewska, K. and Spychaj, T. (2007), "Chemical modification of starch with hexamethylene diisocyanate derivatives", Carbohydrate Polymers, 70, 334-340.

Xiaosheng, D., Hui, C., Rui, D. and Zhihua, S. (2012), "Preparation and Application of Denatured Starches", Journal of the Society of Leather Technologies and Chemists, 96/5, 189-194.

Zhen, J. and Ma, J. (2000), "Modification of starch and its application in leather making", Journal of the Society of Leather Technologies and Chemists, 86, 93-95. 
Investigation of Possible Use of Dialdehyde Corn Starch as Crosslinking Agent in Collagen-based Wound Dressing Materials

=

